\title{
LA ESCRITURA FEMENINA COMO EXPLORACIÓN DE IDENTIDAD PERSONAL Y SOCIAL EN LA NOVELA INGLESA DEL XVIII
}

Ángeles de la Concha

$U N E D$

La eclosión de la crítica literaria feminista en los últimos años y el empeño y esfuerzo subsiguientes por explorar en profundidad no sólo lo que habitualmente se denomina como estado de la cuestión, sino la aportación real de la mujer en el ámbito literario, ha llevado a una intensa labor de rescate de textos largo tiempo relegados al olvido por cánones establecidos antaño y hasta hace muy poco incuestionados. De particular interés resulta esta labor al considerar el periodo que nos ocupa, el siglo XVIII', época que bajo subtitulaciones tan halagüeñamente unificadoras como Edad Augusta, Edad de la Razón o Siglo de las Luces, revela a cuantos se asoman a su interior un panorama harto más complejo y conflictivo, profundamente polémico, foro de discusión social, política y filosófica. La reverencia y preocupación por el decoro, la preceptiva y las normas no eran, en definitiva, sino manifestación de una preocupación más honda ante la ebullición más o menos soterrada pero perceptible, por lo palpitante, de nuevos conceptos,

' Vid. la interesante colección de títulos de Pandora Press, precedida por el estudio de Dale Spender Mothers of the Novel. 100 Good Women Writers Before Jane Austen, London: 1986, interesante también, aunque haya de acogerse con alguna reserva critica. Particularmente valiosa es, asimismo, la publicación An Annotated Bibliography of Twentieth-Century Critical Studies of Women and Literature, 1660-1800, editada por Paula Backsheider y Felicity Nussbaum, New York \& London, Garland, 1977, y A Dictionary of British and American Women Writers, 1600-1800, London, Methuen, 1984. Aparte de su interés crítico general, la obra Fettered or Free? British Women Novelists 1670-1815 incluye un capitulo con bibliografia seleccionada y comentada "The Modern Reader and the "Truly Feminine Novel" 1660-1815 A Critical Reading List», por Roger D. Lund (Eds. Mary Anne Schofield \& Cecilia Macheski, Athens, Ohio \& London, Ohio U. Press, 1986), útil para el lector interesado en el tema. 
valores y aspiraciones que pugnaban por abrir compuertas y rebasar limites ya artificiales.

El crecimiento espectacular de la burguesía y su consolidación en cuanto a prestigio y poder es probablemente el signo externo más contundente respecto al cambio de valores. $\mathrm{Y}$ el individualismo filosófico como soporte ideológico y motor del cambio está en la raíz de un movimiento profundamente revolucionario y, como tal, conflictivo y no exento de contradicciones. La más estridente quizá, y en la base misma del sistema, era la que afirmaba rotundamente el valor incuestionable del individuo, en tanto que lo situaba en el contexto de una dinámica social que, en la práctica, lo iba a denegar con igual rotundidad. Conflicto éste entre los más agudamente sentidos en todos los órdenes y, en consecuencia, centro de reflexión y polémica. Posibilidades de realización individual hasta entonces no entrevistas, se abrian paso despertando impulsos y ambiciones y generando toda una dinámica de oposición a una autoridad moral y real, tradicionalmente establecida, y a una estructura social de nuevo cuño, más dificiles de vencer que lo previsto. Hobbes expresaría con crudeza la paradojica rebaja del valor del individuo en el nuevo orden social al explicitar su carácter relativo, a merced de su cotización en el mercado: «As in other things, so in men, not the seller, but the buyer determines the Price. For let a man (as most men do), rate themselves as the highest Value they can; yet their true value is no more than it is esteemed by others)" ${ }^{2}$.

A fenómenos nuevos, nuevas expresiones. $Y$ la novela va a mostrarse como el género flexible y proteico, particularmente apto para acoger, explorar, interpretar y, finalmente, transmutar en arte este impetuoso caudal, a veces amenazador y a menudo caótico, de posibilidades, ideas y aspiraciones $^{3}$. El individuo, inmerso en el torbellino, abandonado a, o apoyado en, sus propios recursos e imaginación, es el sujeto indiscutible del nuevo género; y su conflicto, conquista de estatus, búsqueda de identidad, exploración de su ámbito y resituación de sus polos de referencia, será la materia de la que éste se nutra ${ }^{4}$. Un subjetivismo, en suma, que con todas las limitaciones que se quiera abre insospechadas posibilidades de prota-

${ }^{2}$ Thomas Hobbes, Leviathan, C. B. Macpherson (ed.), Harmondsworth: Penguin, 1968. p. 152. Trad.: "Ocurre con el hombre, como con otras cosas, que no es el vendedor, sino el comprador, quien determina el precio. Porque dejad que un hombre (como hace la mayoria) se tenga a sí mismo en la más alta estima; su auténtico valor, no obstante, no será otro que el que los demás le otorguen."

"Sobre la relación entre el origen de la novela y la emergencia de un nuevo orden social y filosófico, véanse los ya clásicos, pero diferentes, puntos de vista de Ian Watt, The Rise of the Novel, Harmondsworth, Penguin, 1977 (1." ed. Chatto \& Windus, 1957) y Lucien Goldmann, Pour une Sociologie du roman, París: Gallimard, 1964.

4 Vid. Austin Flanders Wallace, Structures of Experience. History, Society and personal Life in Eighteenth-Century British Novel, Columbia, South Carolina University Press, 1984, particularmente el cap. I. 
gonismo a personajes marginales: sirvientes, pícaros, huérfanos, clérigos y mujeres. Estas últimas no eran ajenas, ciertamente, al universo literario. Su existencia, no como autoras desde luego, pero al menos como presencia, es tan antigua como el arte mismo. Pero con harta frecuencia, si exceptuamos su función alegórica, su aparición constituye el pretexto para la exploración y expresión de los sentimientos del varón, de los que ella es acaso catalizador. Sin generalizar absolutamente, y exceptuando alguna activa heroína del teatro shakespereano, particularmente en las comedias, que, además, recurre al disfraz masculino para llevar a cabo con éxito su empresa, la mujer raramente había alcanzado tal grado de protagonismo. Siempre presente, tanto en la literatura cortesana como en la popular, su función, con todas las cautelas que este tipo de afirmaciones generales requiere, es más como comparsa, pretexto, detonante de acciones o trofeo de empresas.

La irrupción de la mujer en este momento, a la vez como autora y como protagonista absoluta, tiene explicaciones lógicas que se enmarcan en el conjunto de circunstancias que proporcionan el surgimiento y la pujanza del nuevo género.

En primer lugar, y dentro de las consideraciones socioeconómicas tan brevemente apuntadas más arriba, el grupo social femenino, como tal, constituye un elemento a tener en cuenta en la dinámica de fuerzas del mercado. El escritor ha dejado de depender para su subsistencia del mecenazgo de la aristocracia o la Iglesia. Su nuevo patrón va a ser un público no por anónimo menos exigente, ni por plural más contentadizo. El lector, miembro, por lo general, de esta nueva clase burguesa floreciente, en pleno auge, en una época de expansión económica y mercantilista, ejerce unas demandas concretas que el escritor ha de satisfacer. Estos dos polos de referencia, lector/escritor, son cruciales en el establecimiento del género, tanto en el desarrollo de las estrategias narrativas ${ }^{5}$ como en la elección y tratamiento de los temas o la finalidad explícita o subliminal de la obra. La lectura se va a convertir rápidamente en un bien de consumo de una clase acomodada, enormemente mimética de los estratos sociales más elevados, que quiere a toda costa prosperar y disfruta del ocio y los medios necesarios para ello. En su seno la mujer es un objeto de consumo más, extraordinariamente valioso en ocasiones, por constituir el medio principal de ascenso social o de solución de problemas económicos, $y$, en cuanto tal, objeto de particular protección y cuidado.

El bienestar económico tuvo una singular repercusión en el' sector femenino porque, paradójicamente, su liberación de las cargas y responsabilidades inherentes a una economía familiar basada en un alto grado de producción propia lo relegó a un ocio parasitario y paralizante. Por otro

' Vid. Wolfgang Iser, The Implied Reader, Baltimore, The Johns Hopkins University Press, 1974, particularmente la introducción y los capítulos 2 y 3 . 
lado, las muy escasas posibilidades de trabajo fuera del ámbito doméstico reservaban un panorama sombrío a la mujer sin recursos económicos propios que no contraia matrimonio, por lo que su dependencia de la institución era absoluta. La preocupación por prepararla intelectual y moralmente para su único rol social y familiar se evidencia en la multitud de tratados, libros piadosos, manuales pedagógicos e, incluso, artículos en las publicaciones periódicas más en boga. Su objetivo, obviamente, consistía en orientarla de modo casi unilateral al cultivo de las virtudes necesarias para aceptar sin resistencias su destino natural. Recato, modestia, docilidad, ciertos conocimientos - no demasiados- que les permitieran desenvolverse en un ambiente social refinado en el que la conversación era uno de los placeres más cultivados, pero cuyo secreto consistía en la discreción suficiente para apreciar los ajenos sin exhibir los propios --por lo que lo más seguro para un personaje que debia ocupar un lugar secundario era tener los justos-y una religiosidad que amalgamara y procurara una justificación consistente a todo el conjunto, eran los ingredientes básicos y casi exclusivos de su educación.

No es de extrañar que la novela, nuevo género que emergía sin el prestigio de la tradición poética, sin la dignidad de los altos valores ni los aristocráticos héroes de la épica y que recogía, en cambio, abierta o encubiertamente esta problemática femenina, se enjuiciara con suspicacia. Contribuía al recelo su afinidad con el romance en prosa, particularmente el francés del siglo XVII, extraordinariamente popular en la época, al que se atribuian propiedades inflamatorias sumamente peligrosas por imbuir de fantasías y toda suerte de ilusiones debilitantes las mentes femeninas. Fortaleza para asumir función y destino era cuanto se requeria de la mujer, y realmente hay que admitir que la requería en dosis bien altas si había de cumplimentar dignamente ambos.

Razones había para recelar del género, porque la novela, con toda su carga de contradicción inicial, con sus vacilaciones e incoherencias formales y estructurales, se constituyó desde sus inicios en foro de exploración social y moral atrayendo a gran número de escritoras que lo utilizarían como articulación de sus preocupaciones y como planteamiento y respuestas a su situación. Precisamente, la carencia de prestigio por un lado, y las peculiares condiciones de su producción y consumo, por otro, les facilitarían el acceso. La privacidad de la escritura no rompía las rígidas normas del decoro y recato femeninos. Otra cosa era la publicidad del nombre de la autora, escollo más problemático que se obviaba bien con el pseudónimo, muchas veces masculino, o con el ocultamiento hasta que el beneplácito de crítica y público a los valores morales de la obra hacían factible el esclarecimiento. En muchos casos la difusión del nombre traía más problemas que ventajas, pues el fuerte elemento realista de las obras, su verismo y particularización, así como el contenido en ocasiones inspirado o basado en acontecimientos reales, producia inmediatamente una desafortunada asociación crítica de 
orden moral entre autora y obra con funestas repercusiones en la aceptación y difusión del texto. El caso de autoras combativamente feministas cuya conducta no discurría por la estrecha senda reservada a la mujer por la convención y decoro sociales al uso - Mary Wollstonecraft y Mary Hays, por ejemplo- es bien elocuente. Sus novelas levantaron auténticas polémicas y, enjuiciadas siempre desde ópticas ajenas a la literaria, sufrieron todo tipo de obstáculos a su difusión y cayeron pronto en el olvido.

El factor de carencia de prestigio del nuevo género literario y la ausencia, en su caso, de la normativa no por tácita menos rígida, que afectaba a otros ámbitos de las artes y las letras reservándolos al campo de acción masculino, abrió un resquicio a la participación femenina. Las cautelas y estrategias de las autoras al respecto son en si mismas harto elocuentes y revelan más que cualquier manifiesto lo espinoso de la cuestión. Mil justificaciones y excusas prologan modestamente una novela tras otra, las unas aduciendo la finalidad moral de la obra, su objetivo ejemplificador, el bien a que iba a inducir o los males y peligros que iba a evitar; las otras disculpándose por su atrevimiento al invadir un terreno que no les era propio, pero al que la necesidad económica les empujaba. La conciencia de su indefensión como mujeres les lleva, así, en muchos casos a aducirla como medio de despertar la aceptación y la protección masculina ${ }^{6}$. Indefensión que constituye, por otra parte, una de las constantes temáticas del género y que genera una interesante exploración del no menos constante y complementario tema del poder. En este sentido asistimos a una de las más llamativas de entre las muchas paradojas y contradicciones que cohabitan en el género, y que, por otra parte, no es más que un exponente de la realidad recogida por la novela, porque la creación literaria, lejos de ser algo ajeno a esta realidad, es un medio de decirnos algo respecto a ella. Los personajes femeninos, tanto en su papel de autoras como en el de protagonistas, adolecen de una especie

- Vid. a título de ejemplo, el tono criptico de las líneas que dirige Fanny Burney a los críticos con ocasión de la publicación de Evelina:

"Without name, without recommendation, and unknown alike to success and disgrace, to whom can I so properly apply for patronage, as to those who publicly profess themselves Inspectors of all literary performances?

The extensive plan of your critical observations - which, not confined to works of utility or ingenuity, is equally open to those of frivolous amusement, and yet worse than frivolous dullness-, encourages me to seek for your protection, since - perhaps for my sins! - , it entitles me to your annotations.»

Trad.: «Sin nombre, sin recomendación y desconocedora tanto del éxito como del fracaso, ¿a quién mejor podría solicitar protección que a los que se consideran públicamente con facultad para enjuiciar la actividad literaria? El amplio ámbito de su crítica que no se reduce a obras útiles o inteligentes, sino que abarca las de frivola distracción, peores incluso que las de frívolo aburrimiento, me incita a buscar su protección, ya que -quizá por mis faltas- me concede el derecho de recibir sus observaciones.» (Fanny Burney, Evelina. Oxford, Oxford University Press, 1982, p. 3.) 
de división de su personalidad, una suerte de esquizofrenia, como lo define Jane Spencer en The Rise of the Woman Novelist ${ }^{7}$, que se traduce en una conflictiva relación con los miembros de su propio sexo marcada por una dinámica de unión y separación simultáneas. Desde el punto de vista de la autoría femenina, es llamativo el hecho de que mientras se denuncia el doble rasero moral y la hipocresía de costumbres sociales obedientes a criterios escandalosamente mercenarios o a un abuso de autoridad paterna, como el tema de la elección matrimonial, tan crucial por su trascendencia en la vida femenina, se exalte simultáneamente el carácter sumiso, dócil, virtuoso de la mujer que precisamente propicia la continuación del sistema. Pero más llamativo aún resulta el que la propia víctima del sistema - la sufrida protagonista - sea la que, a su vez, lo reproduzca a fuerza de internalizarlo. Un caso evidente es el de la patética heroina de la novela de Frances Sheridan Memoirs of Miss Sidney Bidulph (1761), quien renuncia al hombre de quien está enamorada y contrae un matrimonio sin amor, doblegándose en ambos casos a las presiones de su madre y pasando por la humillación de verse rebajada a mero objeto de transacción comercial: «I thought of the conversations we had so often had about Mr. Faulkland, and could not help considering myself like a piece of goods that was to be shewn to the best advantage to the purchasern" ${ }^{8}$. Repentinamente, a pesar de su rebeldía interior - -I could cry for vexation to be made such a puppet of ${ }^{9}$, , $\ll$ am treated like a baby" ${ }^{10}$ - cede a la decisión materna por un equivocado concepto de amor filial y un masoquismo que se reviste de ropajes considerados como el adorno femenino por excelencia: las virtudes, tan necesarias para estos casos, de resignación y fortaleza: «I am determined to pursue through life that rule of conduct which I have hitherto invariably adhered to; I mean that of preferring to my own the happiness of those who are most dear to me" ", "I was born to sacrifice my own peace to that of other people, my life is become miserable, but I have no remedy for it but patience» ${ }^{12}$; "Sorrows, my Cecilia, soften and subdue the mind prodigiouslys ${ }^{13}$.

' Jane Spencer, The Rise of the Woman Novelist, Oxford, Basil Blackwell, 1986.

" Frances Sheridan, Memoirs of Miss Sidney Bidulph, London, Pandora Press, 1987. Trad.: "Pensaba en las conversaciones que tan a menudo habiamos mantenido sobre el señor Faulkland, y no podía evitar el sentirme como una mercancía que había que exhibir del modo más atractivo posible ante el comprador", p. 118.

'Ibid. "Me daban ganas de llorar de irritación al verme tratada como una marioneta", p. 76.

10 Ibid. "Me tratan como a un bebé», p. 78.

"Ibid. "Estoy decidida a seguir en la vida la misma regla de conducta a la que me he adherido fielmente hasta hoy; quiero decir, la de preferir la felicidad de mis seres queridos a la mía», p. 84.

12 «He nacido para sacrificar mi propia paz a los demás; llevo una vida desgraciada, pero no tengo más remedio que tener paciencia», p. 127.

13 Ibid. «Las penas, mi Cecilia, ablandan y someten la mente de manera prodigiosa». p. 247. 
La vida de Miss Bidulph, un verdadero rosario de dolores, que naturalmente, como el prólogo se encarga de indicar, se nos ofrece con un objetivo ejemplificador y moralizante, podría muy bien erigirse en paradigma de las consecuencias desastrosas que las imposiciones maternas en conjunción con una indiscriminada sumisión filial pueden traer. Pero nuestra admiración no puede por menos de acrecentarse al penetrar en la confidencia de la heroína a su mejor amiga, en el sentido de que su amor por su hija recién nacida es tal que, igual que ella ofreció a su madre el don total de sí misma, la obediencia absoluta a sus deseos en justa correspondencia a su cariño, no puede por menos de esperar, a su vez, lo mismo de su hija: «Then I say, surely I have a right to all the duty, all the filial love that this creature can show me, in return for my fondness ${ }^{14}$. El amor y el deber es un ambiguo juego de conceptos, un instrumento de manipulación y chantaje afectivo que encubre sublimaciones y fantasías masoquistas. No es extraño que el amor se exprese a menudo en imágenes desoladoras, el fuego breve casi extinto, la casa helada, cadenas, locura y muerte. Menos extraño aún es que apenas existan en estas novelas figuras paternas y menos aún maternas. Cuando existen, son casi invariablemente las responsables del conflicto y la desgracia de sus hijas.

El resto de los personajes femeninos que rodea a las protagonistas reproduce muy a menudo un patrón parecido de víctimas y victimizadoras. El carácter fuerte, la toma de decisiones, la energía y la independencia se encarnan curiosamente en estereotipos femeninos negativos y planos que funcionan como antagonistas a la heroína cuyas virtudes femeninas realzan por contraste. Paradójicamente, la protagonista ha de recurrir para su salvación o simple subsistencia a una figura masculina, en general mentor/ amante, y marido, luego. Es un patrón sigular que configura la organización familiar subyacente a la estructura de esta novela de autoras femeninas. The History of Miss Betsy Thoughtless (1751), de Eliza Haywood; The Female Qixote (1752), de Charlotte Lennox; Evelina (1778), de Fanny Burney; A Simple Story (1791), de Elizabeth Inchbald; The Mysteries of Udolpho (1794), de Ann Radcliffe; The Memoirs of Emma Courtney (1796), de Mary Hays; todas presentan heroinas huérfanas, lo que permite una exploración un tanto más libre del ya de por si confinado espacio femenino. La ausencia de vínculos familiares directos permite proyectar los conflictos de forma subrogada en la figura de madrastras o guardianes que, encarnando la misma autoridad abusiva que los padres, hacen más permisible y aceptable la crítica —en el fondo- al sistema, puesto que la resistencia de la heroína no viola las convenciones inamovibles de respeto, amor y obediencia debidas a los progenitores naturales. Por otro lado, permite exponer con mayor

14 Ibid. «Entonces me digo, de seguro tengo derecho a todo el deber, todo el amor filial que esta criatura pueda mostrarme en correspondencia a mi cariño», p. 10. 
crudeza las ạuténticas motivaciones económicas tras esa autoridad abusiva de los padres.

La internalización de los valores establecidos por el grupo social que detenta el poder por parte de los grupos menos privilegiados a la búsqueda más o menos consciente de una aprobación y aceptación, es un dato sociológico constatado en todas las culturas y se confirma en el caso que nos ocupa. La mujer escritora internaliza los valores en auge entre el sector dominante, el masculino de las clases altas, del que depende, entre otras cosas, por su monopolio de resortes clave en la producción literaria: ediciones, críticas, periódicos, que determinan en muchos casos la trayectoria del producto. A ello hay que atribuir la postura de superioridad moral que adopta la propia mujer con respecto a los restantes miembros de su mismo sexo, sin caer en la cuenta de que no son menos víctimas que ella de esa situación injusta que sufre y denuncia. Y ello ocurre asi aun en el caso de escritoras abiertamente feministas, como Mary Hays con su obra en parte autobiográfica The Memoirs of Emma Courtney, que revela patéticamente la contradicción en el corazón de un sistema que proclama los valores del individuo al tiempo mismo que le cercena la posibilidad de realizarlos. Emma encarna una por una las contradicciones personales y sociales que envuelven la condición femenina ${ }^{15}$, y la novela gira en torno a los intentos de la protagonista por definir su propia entidad y crecer como persona mediante la educación intelectual, y la posibilidad de decidir entre fuerzas que operan en sentidos opuestos. Por un lado, el impulso interior hacia una vida más plena e independiente, dotada de mayor significado a la que Emma intuye que se accede con la llave del conocimiento y el saber. Por otro, la atracción casi insensible pero igualmente poderosa hacia la sumisión emocional e intelectual en la pasión amorosa. Huérfana de madre desde muy niña y abandonada prácticamente por un padre indiferente que dilapida su fortuna, se ve obligada a enfrentarse a la vida con sus propios recursos, después de pasar por la tutela de unos parientes indulgentes y benévolos que le procuran la educación banal que el siglo consideraba adecuada y suficiente para las jóvenes. Su inquietud personal y la biblioteca de su padre le permiten acceder a unos conocimientos más profundos y a una independencia de juicio moral y social que, en definitiva, le traerán más disgustos que ventajas. Aislada de las de su sexo que le impacientan con su frivolidad, poco juicio y limitadas aspiraciones, y reducida a una existencia confinada y asfixiante, sin horizontes, su vida se precipita hacia la tragedia, arras-

$13 \mathrm{Vid}$. el excelente estudio de Janet Todd sobre el conflicto entre la esperanza de ver aceptados planteamientos racionales como punto de partida para la cuestión femenina y la conciencia de la supremacia de una ideologia cultural que aprisionaba a la mujer en las coordenadas de la sensibilidad y en los mitos de la novela sentimental, en Janet Todd, The Sign of Angelica, Women Writing and Fiction, 1660-1800. London, Virago, pp. 236-252. 
trando con ella a los que la rodean. El conocimiento, ese anhelado instrumento de poder reservado al mundo masculino, no le procura la energía moral para sobreponerse a una pasión imposible ni los medios para una independencia económica que le libre de un matrimonio por conveniencia que terminará en fracaso. La ansiada independencia intelectual y moral no le salva de la dependencia económica ni emocional que le traerán la desgracia.

El final trágico es la única alternativa posible al convencionalmente feliz del matrimonio con el héroe que libra a la protagonista de los riesgos que su indefensión, indigencia o inocencia le deparan. Veremos, así, en la novelística de este período, tanto la femenina como la masculina escrita desde la óptica de aquélla, el arranque y progresiva consolidación de dos tradiciones ${ }^{16}$ que se afianzarán en la narrativa posterior: la novela de seducción o de una pasión imposible, con desenlace trágico, y la novela de crecimiento o reforma que explora el progreso intelectual, moral y social de su heroína y que concluye con el clásico final feliz del matrimonio como recompensa. En ambos casos la peripecia patentiza la problematicidad de la condición femenina de la que el género novelesco se hace eco. En la base de ambas trayectorias se encuentra el conflicto entre obediencia y resistencia que la mujer tenía que resolver en su propia vida antes de iniciarse en su actividad como escritora y que, como Elaine Showalter analiza ${ }^{17}$, se expresa en sus novelas como el nudo de la crisis moral de sus heroínas. Si la protagonista se somete y se "reforma", el desenlace suele ser feliz, excepto en algún caso aislado como el de Miss Sidney Bidulph, aunque la autora se encargaba de advertirnos en la introducción que hay casos en los que la fidelidad a la Naturaleza por encima del Arte justifican la transgresión de la justicia poética. Si en el conflicto triunfa la resistencia sobre la obediencia, e] desenlace es indefectiblemente trágico.

No es extraña la popularidad que alcanzaron estas obras, seguidas fervorosamente por un público femenino cada día más numeroso que se reconocía e identificaba en personajes y problemática, porque la estrecha dependencia económica que veíamos se creaba entre el autor y su nuevo patrón, el público, favorecía el empeño del primero en proporcionar a su cliente lo que deseaba leer. "Altering our imaginations, fiction may alter our lives», observa Patricia M. Spacks en Imagining a Self. Autobiography and Novel in XVIIIth-century England ${ }^{18}$, y efectivamente, el estimulo que

16 Jane Spencer, op. cit., pp. 107 y ss.

17 Elaine Showalter explora este conflicto en la novelística de escritoras del siglo xIX, pero es perfectamente válido en el caso de sus antecesoras del xvIII. Vid. A Literature of Their Own. British Women Novelists from Brontë to Lessing, London, Virago, 1978, p. 24.

${ }_{18}$ Patricia M. Spacks, Imagining a Self. Autobiography and Novel in Xvilth-century England, Cambridge (Mass.), Harvard U. Press, 1976, p. 11: «Al hacer cambiar nuestra imaginación la novela puede cambiar nuestra vida.» 
estas lecturas procuraban a la imaginación y la vivencia, bien que vicaria, de posibilidades impensables en la vida real pero perfectamente factibles no obstante, gracias a la ilusión de verismo e individuación formal y contextual, dieron lugar a no poca controversia sobre la peligrosidad moral del género. Richardson lo apuntaba en Clarissa, recogiendo por medio de Lovelace la opinión del sensato capitán Morden al respecto: «He said that men had generally too many advantages from the weakness, credulity and inexperience of the fair sex: That their learning, which chiefly consisted in inflaming Novels and idle and improbable Romances, contributed to enervate and weaken their minds» ${ }^{19}$. No sólo Richardson, sino incluso una novelista tan ortodoxa como Fanny Burney, en una novela tan educativa como Evelina, se pronuncia con su característica ironía y ambivalencia a favor y en contra a la vez ${ }^{20}$. Con el correr del siglo, Mary Wollstonecraft abunda en el mismo tema, asociándolo igualmente al problema de la educación femenina en general, a cuya ausencia de vigor intelectual y moral achaca la debilidad de juicio que se atribuye a la mujer, su pernicioso sentimentalismo, su vacuidad moral y, como corolario, la indefensión a que la reduce ${ }^{21}$.

19 Cit. en Margaret Anne Doody, A Natural Passion. A Study of the Novels of Samuel Richardson, Oxford: Clarendon Press, 1975, p. 128. Véase el capitulo «Clarissa and Earlier Novels of Love and Seduction". Trad.: "Decía que los hombres tenían demasiadas ventajas debido a la debilidad, la credulidad y la inexperiencia del bello sexo: que su educación temprana, que consistía, sobre todo, en novelas inflamatorias y romances simples e inverosimiles, contribuian a enervar y debilitar sus mentes."

${ }^{20}$ Fanny Burney, op. cit., p. 8. «Quizá, si fuera posible extirpar de raíz las novelas, su aniquilación sería beneficiosa para nuestras jóvenes en general y nuestras damiselas en los internados en particular. Pero como la dolencia que han propagado parece incurable, como el contagio desafia la medicina del consejo o de la reprimenda, y como se ha constatado que resisten cualquier tratamiento que no sea el prescrito por el lento régimen del Tiempo y la amarga dieta de la Experiencia, de seguro han de alentarse y no condenarse todos los intentos de incrementar el número de las que pueden leerse si no con provecho, al menos sin daño."

${ }^{21}$ En Mary, a Fiction hace una crítica devastadoramente irónica al describir la afición a estas lecturas de la indolente e inane madre de la protagonista: "As she was sometimes obliged to be alone, or only with her French waiting-maid, she sent to the metropolis for all the new publications, and while she was dressing her hair, and she could turn her eyes from the glass, she ran over those most delightful substitutes for bodily dissipation, novels. (...) She was chaste, according to the vulgar acceptation of the world, that is, she did not make any actual faux pas; she feared the world, and was indolent; but then, to make amends for this seeming selfdenial, she read all the sentimental novels, dwelt on the love-scenes, and, had she thought while she read, her mind would have been contaminated; as she accompanied the lovers to the lonely arbors, and would walk with them by the clear light of the moon.» Mary Wollstonecraft, Mary and The Wrongs of Woman, Oxford: Oxford University Press, 1976, pp. 2 y 3. Trad.: «Como a veces se veia obligada a estar sola o con su doncella francesa por toda compañia, encargaba en la capital las últimas publicaciones y cuando se arreglaba el cabello y podia tornar la mirada del espejo, recorría esos deliciosos sustitutos de disipación corporal: las novelas. (...) Era casta, de acuerdo con la vulgar acepción del término, esto es, no habia dado un paso en falso; temía al mundo y era indolente; pero entonces, para compensar esta aparente autodisciplina, leia todas las novelas sentimentales, se recreaba en las escenas de amor, 
Las heroínas de estas novelas se esfuerzan en cultivar la mente, aunque son conscientes de que con frecuencia su interés se observa con más recelo que aprobación. Miss Sidney Bidulph se excusa ante su futuro marido, que la sorprende con un libro de griego entre las manos, asegurándole que dedica más tiempo a la aguja que a los libros ${ }^{22}$, Emma Courtney se ve ridiculizada en público por un caballero que considera que el conocimiento y el saber resultan insufribles en las damas ${ }^{23}$.

Un rasgo muy significativo de estas novelas es el profundo pesimismo que reflejan y que cristaliza en un desenlace con frecuencia morboso. Cuando la heroína despierta a la realidad de un mundo en el que no hay lugar para el tipo de mujer que quiere ser, deja de luchar y muere. El desenlace se presenta unas veces como remordimiento y castigo, como en el caso de Miss Milner en $A$ Simple Story ${ }^{24}$, en el que la flagrante transgresión por parte de la protagonista de las normas morales y sociales no puede terminar más que con el arrepentimiento, el destierro y la muerte, simplemente de decaimiento gradual y languidez. En otros casos, la muerte es una decisión voluntaria, meditada y deseada, no provocada directamente, pero acogida con gozo, como Clarissa, fruto de la oposición inviolable a las demandas de una estructura familiar y social considerada injusta. En otros, finalmente, no es más que la culminación lógica de una existencia que discurre por círculos cerrados. La frustración afectiva, la inminencia de un matrimonio no deseado como único horizonte, la soledad y la reducción del cultivo de la mente al sentimiento y a la sublimación de una existencia infeliz desembocan en apatía y estado de profunda melancolía y anticipación de la muerte como única liberación. «Her delicate state of health did not promise long life» -leemos en Mary, a Fiction, de Mary Wollstonecraft- - "In moments of solitary sadness, a gleam of joy would dart across her mind. She thought she was hastening to that world where there is neither marrying, nor giving in marriage ${ }^{25}$. La conclusión, de por sí melancólica, cobra tintes más sombrios cuando se recuerda la propia vida de la escritora, ardiente defensora de unos derechos femeninos tan elementales que hoy día nos parecen asunto de ficción. Mary Wollstonecraft pagó con experiencias similares -incomprensión, soledad, depresión, intentos de suicidio- su esfuerzo en favor del

y si hubiera reflexionado mientras leía, su mente se habría contaminado, ya que acompañaba a los amantes a sus rincones solitarios en la arboleda y paseaba con ellos a la clara luz de la luna.»

2 Frances Sheridan, op. cit., p. 73.

23 Mary Hays, Memoirs of Emma Courtney, London, Pandora Press, 1987, p. 22.

24 Elizabeth Inchbald, $A$ Simple Story, London, Pandora Press, 1987, p. 175.

25 "Su delicado estado de salud no auguraba larga vida. En momentos de solitaria tristeza, un rayo de alegría cruzaba su mente. Pensaba que se apresuraba hacia ese mundo en el que no existe ni el matrimonio ni la entrega en matrimonio." Mary, a Fiction, op. cit., p. 68. Alusión a la vida futura en los Evangelios, Mt., 22, 22-30, o Lc., 20, 27-40. 
ensanchamiento de los circuitos existenciales de la mujer. La ironia final de su vida le aguardaba en la muerte, femenina donde las haya, de complicaciones de postparto.

La tradición de la novela de reforma que recoge el progreso moral y social de la protagonista es mucho más optimista, y también menos radical, aunque discurre por cauces narrativos similares e incurre en parecidas contradicciones. La inocencia de la heroína y su desconocimiento de los usos sociales le permite una visión crítica del medio en que se desenvuelve, aceptable al propio medio que la justifica o la tolera en razón de su ignorancia e inexperiencia. La voz del narrador lleva a cabo una labor de filigrana al aceptar y subvertir a la vez de forma en extremo sutil los valores establecidos. The Story of Miss Betsy Thoughtless, The Female Quixote y Evelina son jalones de una tradición que culminará con insuperable brillantez y maestría en Jane Austen.

La problemática que presenta esta corriente es muy interesante porque viene a conferir encarnadura a un debate ideológico de enorme trascendencia en la época: el suscitado por el conflicto entre las categorias de los universales y los particulares que encubre en un momento de pugna por la supremacia entre individuo y especie, un conflicto latente, pero muy real, de poder. La convención del nombre ${ }^{26}$, esto es, el acuerdo respecto a su significado, respecto a la definición correcta de la realidad tras él, es la herramienta imprescindible de la ciencia. De ahi la importancia que se concedió a la fijación del sentido de los términos plasmada en la ingente empresa del Diccionario de Johnson, por ejemplo, o en el desarrollo de los sistemas clasificatorios y la ciencia de la taxonomía.

El gran riesgo del sistema de nombrar se evidencia inmediatamente en cuanto se aproxima a la esfera de lo humano, ya que el otorgar un nombre a una persona implica definir su naturaleza, funciones y uso: hombre, mujer, niño. El riesgo aumenta con la consideración del campo semántico pertinente. En el caso que nos ocupa, el relativo a la mujer, con frecuencia los sistemas de clasificación, bajo apariencia de exaltación de su naturaleza, lo que realmente producen es una devaluación de su humanidad y, naturalmente, de su individualidad. Porque el nudo de la cuestión radica en quién clasifica, a quién se le reconoce o quién se arroga la capacidad para nombrar y con ello para determinar y definir la naturaleza y funciones de lo definido.

Locke, que ya había ilustrado ampliamente el carácter arbitrario, artificial, de los nombres', recalcó, asimismo, su carácter subjetivo y privado: "And every Man has so inviolable a liberty to make words stand for what ideas he pleases that no one has the power to make others have the same

26 Vid. el interesante estudio de Michael Ragussis, Acts of Naming. The Family Plot in Fiction, Oxford: Oxford University Press, 1986, que, aunque incide en los nombres propios, contribuye a esclarecer la cuestión, particularmente el cap. I sobre Clarissa, pp. 19-34. 
ideas in their minds that he has when they use the same words that he does ${ }^{27}$. La rotundidad de la teoria no tardaria en verse desmentida en la práctica a cada paso, porque la realidad mostraba que quien tenía el poder de nombrar tenía, asimismo, la autoridad de imponer, y el sujeto nombrado acababa por internalizar el concepto y por plegarse a la función y al uso atribuidos a su supuesta naturaleza. El concepto mujer se revelaría, no obstante, como una categoría en extremo cuestionable y la novela recogería la dialéctica en torno al conflicto suscitado por la constatación de que lo femenino no era algo estático que pudiera encarnarse en un arquetipo de perfección o vicio, según recogiera los atributos o los pervirtiera. Jane Spencer analiza esta incipiente novedad en el tratamiento dinámico del carácter femenino que dará lugar a una de las más sólidas y productivas tradiciones literarias dentro de la novela escrita por mujeres, contraponiéndola a las heroínas de estática bondad y belleza de Fielding o Smollett ${ }^{28}$.

El objetivo moral que justificaba la actividad de la escritura femenina encontró un amplio espacio de posibilidades dentro de una convención general que contemplaba la reforma moral en pequeña escala, esto es, de errores disculpables en razón a la edad, la ignorancia o la inexperiencia. Los pecados más graves se reservaban para los personajes secundarios que, además de realzar por contraste la bondad innata de la heroína, contribuían a resaltar el objetivo moral mediante los castigos ejemplificadores que el destino reservaba a sus acciones. Siendo el matrimonio la piedra de toque en torno a la cual giraba la existencia femenina, no es extraño que igual que el premio a su reforma consistía en el matrimonio con el aspirante perfecto a su mano, cuyas singulares cualidades justificaban la adaptación de la protagonista a la norma, el castigo radicara también en el matrimonio; en este caso, con un cónyuge que se encargaba de asegurar la confabulación de todos los horrores a los que tal estado de vida era susceptible, que no eran pocos.

La trascendencia del matrimonio como acontecimiento clave en la vida, y determinante en tantos casos de la felicidad o desgracia femenina, justifica su centralidad en el universo de la ficción; y el período de breve cortejo que lo precede se convierte en un importante espacio de ilusión de protagonismo, de conciencia de la propia importancia y, lo que es más sugestivo, de fantasías de poder. Es la única circunstancia en que hasta las reglas del decoro, tan rígidamente acatadas, prescriben la sumisión masculina, lo que en sí

"John Locke, An Essay Concerning Human Understanding, ed. Peter H. Nidditch, Oxford: Oxford University Press, 1975, p. 408. "Y todo hombre tiene una libertad tan inviolable de hacer que las palabras signifiquen las ideas que le parezcan, que nadie tiene el poder de hacer que otros tengan en su mente las mismas ideas que él tiene cuando utilizan las mismas palabras que él."

28 Jane Spencer, op. cit., p. 140. 
mismo constituye en ocasiones una especie de test de audacia mediante el cual la mujer mide sus fuerzas y su capacidad de poder. "Why did I not keep him longer in suspense?»-se pregunta Miss Milner en $A$ Simple Story - «He could not have loved me more I believe; but my power over him might have been greater stillı ${ }^{29}$. El experimento no siempre es feliz, como la triste historia de Miss Milner atestigua. Otras veces la situación es reversible y la protagonista, duramente castigada por su ligereza y coquetería, como Miss Betsy Thoughtless, recupera a su amante y pueden aún, reformados ambos, aunque ella más, emprender una vida en común prometedoramente dichosa.

El hecho de que el final feliz de la novela tenga lugar invariablemente antes del matrimonio revela una cautela en sí misma bastante significativa; y es que con la ceremonia nupcial terminaba la fantasía, y la ficción tropezaba con el más pantanoso tema de la realidad.

Comentábamos más arriba la escasa estima literaria de que gozó el género en sus inicios por su asociación con los romances tardios en prosa, particularmente los franceses, desbocadamente románticos y absurdos. Quizá como reacción defensiva para evitar comparaciones en demérito de su obra, es en todo momento patente el esfuerzo del autor, y en esto apenas existen diferencias en cuanto al sexo, por conseguir retratos auténticos, psicológicamente verídicos, y por dotarlos de un marco de referencia sólidamente pormenorizado. Hemos visto que la preocupación central de la novelística femenina es la dificultad de descubrir y forjar su propia identidad entre las mil dificultades y paradojas que estorban el crecimiento de la mujer como persona. Autobiografia, memorias y relato epistolar son recursos formales que inciden en la ilusión de verismo y se revelan como instrumentos singularmente eficaces para expresar este enorme esfuerzo de interpretación del sentido de la vida, de racionalización de la experiencia y reconciliación con unas premisas de otro modo insoportables. La efusión personal y la relativa sinceridad que la convención formal permite propician una comunicación más directa con el lector, al que se erige en confidente, y en consecuencia, una involucración emocional más intensa. La vida interior, los delicados mecanismos que regulan la percepción moral y orientan decisiones de incalculable trascendencia tras su apariencia menor, el papel de la imaginación y el sentimiento, su control por la razón, las demandas que la sociedad ejerce sobre la mujer, la resístencia y, no obstante, la afirmación final del mismo orden social que la limita, son preocupaciones de la vida real que las escritoras proyectan en sus personajes.

Esta ambivalencia final se expresa también en el orden formal en fisuras que contradicen o al menos recortan tanto la ideología inicial como el efecto

29 Elizabeth Inchbald, op. cit., p. 119. «¿Por qué no le mantendría más tiempo en suspense? Creo que no podría quererme más, pero mi poder sobre él habría sido aún mayor.» 
de convicción y autenticidad que las novelas persiguen. El pretexto para la escritura de las memorias en The Memoirs of Emma Courtney es irritante, o patético cuando menos, ya que esgrime como justificación de las mismas el eterno argumento para impedir a la mujer el pronunciarse con autonomía en el tema matrimonial. Emma relata sus desgracias al hijo del hombre a quien amó sin ser correspondida y al que tras una serie de rocambolescos incidentes adoptara como propio, sin hasta entonces revelarle la identidad de su padre ni la historia de sus relaciones mutuas. El objetivo que aduce es que el ejemplo de los imprudentes matrimonios tanto de su padre como de ella misma le sirvan para no incurrir en el mismo error. En Memoirs of Miss Sidney Bidulph, las cartas que Miss Sidney escribe a su amiga Cecilia, y que sirven de estructura a la novela, son tanto técnica como emotivamente imposibles, e incluso de vez en cuando confia la redacción de su diario a su doncella con el pretexto de su ocupación o preocupación excesivas, cuando obviamente no le interesa entrar a fondo en un tema. Y con toda la distancia que las autoras quieran marcar respecto a los romances, no faltan elementos fantásticos, coincidencias improbables, raptos, disfraces, fortunas que surgen y se esfuman, hijos perdidos, identidades recobradas, y, sobre todo, la recompensa y el castigo finales para héroes y villanos propias del género.

Una divertida parodia de los romances franceses en prosa del XVII y de sus calenturientos efectos sobre las mentes femeninas es The Female Quixote, de Charlotte Lennox ${ }^{30}$, que como su nombre implica, es una réplica femenina al Quijote, de Cervantes, la obra que mayor influencia ejerció en Inglaterra en el siglo XviII. Como tal réplica, la universalidad del Quijote español se encoge en la versión inglesa femenina para convertirse en miniatura satírica de las fantasías del poder femenino cultivadas por el romance. Arabella, la protagonista, vive como Don Quijote una ficción ilusoria, adaptando cómicamente la realidad a su fantasia. Como las heroínas de los romances que parodia, se cree centro de su universo y dueña de un omnimodo poder sobre sus pretendientes. Su ignorancia absoluta del mundo, merced a la vida de reclusión en su casa de campo a la que su padre la ha tenido sometida, no hace sino favorecer esa enajenación ilusoria que convierte su existencia confinada en una permanente aventura. El choque en sus primeros contactos con los elegantes núcleos de Bath y Londres es pretexto para una crítica social cómica y amable a lo largo y ancho de un sin fin de aventuras de corte muy similar que surgen al pretender aplicar a la vida cotidiana el código de honor, la ética y las expectativas del romance. La autora presenta el universo ilusorio de Arabella como el refugio y la evasión de su existencia sometida, confinada y anodina. De hecho, la novela, que pertenece a la tradición didáctica de heroinas reformadas, se centra en

30 Charlotte Lennox, The Female Quixote, London, Pandora Press, 1986. 
el breve período de cortejo previo al matrimonio con un primo suyo con el que su padre quiere casarla. Arabella no hace sino alargarlo a toda costa -como ocurría en sus modelos de ficción, en los que con la boda terminaba el romance- imponiendo prueba tras prueba a su paciente enamorado para medir la fortaleza de sus sentimientos con la piedra de toque del sometimiento a su voluntad. Tras múltiples peripecias y aventuras que no hacen sino poner de relieve el carácter generoso y la enajenación ridícula de su protagonista al alimentar una utópica fantasía de independencia y dominio, el desenlace contempla a una Arabella restablecida, recobrado el juicio y reconciliada con la existencia real. Ello implica la renuncia al omnímodo e ilusorio poder de la heroína del romance y el sometimiento voluntario a la vida convencional, uniforme y sin historia reservada a las mujeres, descrita por la bondadosa condesa que contribuye a su «curación». De este modo, con el peculiar arte que muestran estas novelas para dramatizar el conflicto entre el instinto natural de la mujer a la independencia y la presión social del entorno hacia la conformidad, subvirtiendo en un principio las coordenadas sociales para afirmarlas al final, nos queda la ambivalente y ambigua sensación de que la realización de la mujer es posible sólo en el mundo seguro de la protección masculina y pasa forzosamente por la renuncia a la imaginación, la acción y el riesgo.

Si The Female Quixote ponía de manifiesto que la fantasía era el único ámbito abierto a la iniciativa, la acción y la aventura femeninas, puesto que las que la vida real ofrecia a las mujeres en seguida revelaban su faz licenciosa e ilícita, como los argumentos y personajes secundarios - Miss Groves, por ejemplo-, se encargaban de mostrar el género conocido como gótico por su predilección por épocas remotas, sobrecogedores parajes, lóbregas mansiones y ruinas sombrias, daba rienda suelta a la imaginación al librarla de las ataduras y convenciones del realismo formal. El entorno y el peligro que acechan a la heroina la dispensan de los apuros insípidos o los dilemas triviales de la vida social cotidiana que tan pormenorizadamente recogía la novela realista para transportarla a una atmósfera excitante plagada de peligros y aventuras en la que se ponía a prueba sus dotes personales de fortaleza, presencia de ánimo, valor y energía. La amplitud de la panorámica espacial y temporal procuraban un ancho escenario y libertad de movimientos a los personajes para recorrer exóticos circuitos imaginativos sin otra pretensión de realismo que despertar un fuerte sentimiento de identificación emocional con el tumulto interior de la heroína. Empresa no difícil porque en la base de la trama encontramos una vez más las claves que configuraban la experiencia femenina: la indefensión a manos de la propia familia para quien la mujer era tantas veces objeto de transacción o presa sexual.

En The Mysteries of Udolpho, de Ann Radcliffe, encontramos los elementos usuales de la peripecia femenina con trazos más vivos y fulgor siniestro. La mujer acosada es la imagen central. En su torno se tejen toda 
suerte de estratagemas y lazos en un clima opresivo de asechanza y hostigamiento. El valor de la heroína, su presencia de ánimo, el periplo de su huida y las escaramuzas en el intento convierten este género en una suerte de picaresca ${ }^{31}$. Emily, la protagonista, recorre multitud de lugares y está expuesta a todo tipo de rigores y peligros. La amenza es a menudo de tipo sexual, creándose una atmósfera morbosa de implicaciones sombrías en las oscuras estancias y los laberínticos corredores del castillo. La figura perversa de Montoni, con su aire byroniano, diabólico y fascinante, preside la trama encarnando el tumultuoso y complejo mundo subterráneo de la pasión y la seducción fatal. La autora combina la atmósfera emocional, impregnada de oscura fascinación sexual, con la explicación racional y con una pedagogía de control del sentimiento como eficaz instrumento de defensa femenina.

El género gótico procuró una alternativa a la expresión de sentimientos soterrados y reprimidos, una válvula que en términos surrealistas liberaba energías a la vez que daba configuración plástica a terrores más reales de lo que se quería pensar y admitir. Mary Wollstonecraft, por ejemplo, recogería elementos de este género gótico sin ningún ánimo de fantasía, sino en su empeño riguroso de despertar la conciencia social a zonas de la realidad que se preferia ignorar. Asi, en Maria, or The Wrongs of Woman, la protagonista, recluida por su marido en una especie de manicomio o casa de "reposo", con el fin de desposeerla de su fortuna, sufre los terrores nocturnos del lugar y el tormento de su imaginación y su mente. Y Elaine Showalter, en su documentado y fascinante estudio The Female Malady, recoge instancias similares en novelas ya en el siglo $\mathrm{XIX}^{32}$.

Resumiendo, quizá lo más interesante de esta corriente de escritura femenina en el siglo XVIII que cristalizará ya pujante, depurada y refinada en el XIX, sea la consagración como materia de inspiración y creación literaria de la sustancia de la vida cotidiana. Una realidad no por cercana o trivial desprovista de urgencia. Muy al contrario, situaciones políticamente incuestionadas por lo arraigado de su implantación social van a cobrar protagonismo, a despertar polémica, a articular y dar expresión aunque de modo contradictorio, con la indeterminación de lo incipiente, a una afirmación de conciencia y sensibilidad indiscutiblemente femeninas, esto es, desde la óptica y la perspectiva específica de la mujer y su problemática. Integridad moral y sensibilidad emocional serán los rasgos icónicos que establecerá en la imaginación popular la figura casi emblemática de un ideal femenino contra un trasfondo social complejo, a menudo hostil, cuyo entramado deberá sortear en un alarde de equilibrio entre la autoafirmación individual y el sometimiento social. Es sintomático, en este sentido, la sen-

"Vid. Eva Figes, Sex \& Subterfuge. Women Writers to 1850, London, Macmillan, 1982, p. 72 .

"2. Elaine Showalter, The Female Malady, London, Virago, 1987, p. 126. 
sibilidad y el espiritu alerta que se aprecia en esta escritura hacia la escena, los usos y los comportamientos sociales. Y fruto de ello, la estrecha y recíproca relación que establecen sus autoras entre el mundo real que describen y el imaginario que construyen. No puede extrañar, entonces, la respuesta y la adhesión de un público femenino que reaccionaba ante la urgencia y la ansiedad soterradas en temas tan familiares, ante las figuras y situaciones que estas novelas le mostraban y que directa o indirectamente le devolvian su propia imagen, o en cualquier caso, dramatizaban su núcleo existencial, el conflicto, en definitiva, en el establecimiento de su identidad personal y social.

Desde el punto de vista formal, el interés radica en las estrategias de expresión, en la manera indirecta de afirmar, en el potencial subversivo, de largo alcance, de la contradicción, y en las sutiles tácticas de encubrimiento de los impulsos más desestabilizadores a fin de dotar a las ficciones de una fachada y un decoro que las hicieran social y editorialmente aceptables. Temas conflictivos, a menudo impopulares y en ocasiones abiertamente imposibles, encuentran, así, cauce, aunque sea subliminal, en un subtexto que al entreverar y densificar el texto, difumina las líneas de la ficción, extendiendo el ámbito de sugerencia, multiplicando niveles de interpretación y abriendo, en consecuencia, una posibilidad de cambio. 